\title{
Using Community-Based Participatory Research to Design, Conduct, and Evaluate Randomized Controlled Trials with American Indian Communities
}

\author{
Elizabeth Rink, PhD, MSW ${ }^{1}$; Kelly Knight, $\mathrm{PhD}^{2}$; Colter Ellis, $\mathrm{PhD}^{2}$; Alma McCormick, $\mathrm{BS}^{3}$; \\ Paula FireMoon, $\mathrm{MA}^{4}$; Suzanne Held, $\mathrm{PhD}^{1}$; Eliza Webber, $\mathrm{MPH}^{5}$; Alexandra Adams, MD, $\mathrm{PhD}^{5}$
}

\begin{abstract}
Accessible Version: www.cdc.gov/pcd/issues/2020/20_0099.htm
Suggested citation for this article: Rink E, Knight K, Ellis C, McCormick A, FireMoon P, Held S, et al. Using CommunityBased Participatory Research to Design, Conduct, and Evaluate Randomized Controlled Trials with American Indian Communities. Prev Chronic Dis 2020;17:200099. DOI: https:// doi.org/10.5888/pcd17.200099.
\end{abstract}

\section{PEER REVIEWED}

\section{Summary}

What is known about this topic?

Research is needed to provide ways to implement randomized controlled trials (RCTs) in Indigenous communities using community-based participatory research (CBPR) practices and principles.

\section{What is added by this report?}

We used a multiple case study research design to examine how Tribal $\mathrm{Na}$ tions and researchers collaborated to develop, implement, and evaluate CBPR RCTs.

What are the implications for public health practice?

Tribal-academic partnerships using CBPR RCTs must balance tribal community interests with colonial scientific rigor and use outcomes that include tribal community concepts of success as well as outcomes found in standard colonial scientific research practices.

\section{Abstract}

\section{Purpose and Objectives}

Academic literature indicates a need for more integration of Indigenous and colonial research systems in the design, implementation, and evaluation of randomized controlled trials (RCTs) with American Indian communities. In this article, we describe ways to implement RCTs with Tribal Nations using community-based participatory research (CBPR) principles and practices.

\section{Intervention Approach}

We used a multiple case study research design to examine how Tribal Nations and researchers collaborated to develop, implement, and evaluate CBPR RCTs.

\section{Evaluation Methods}

Discussion questions within existing tribal-academic partnerships were developed to identify the epistemologic, methodologic, and analytic strengths and challenges of 3 case studies.

\section{Results}

We identified commonalities that were foundational to the success of CBPR RCTs with Tribal Nations. Long-standing community-researcher relationships were critical to development, implementation, and evaluation of RCTs, although what constituted success in the 3 CBPR RCTs was diverse and dependent on the context of each trial. Respect for the importance of diverse knowledge systems that account for both Indigenous knowledge and colonial science also contributed to the success of the RCTs.

\section{Implications for Public Health}

Tribal-academic partnerships using CBPR RCTs must include 1) establishing trusted CBPR partnerships and receiving tribal approval before embarking on RCTs with Tribal Nations; 2) balancing tribal community interests and desires with the colonial scientific rigor of RCTs; and 3) using outcomes that include tribal community concepts of success as well as outcomes found in standard colonial scientific research practices to measure the success of the CBPR RCTs. 


\section{Introduction}

Intervention science highlights the need for the integration of Indigenous-based theories and knowledge systems, communitybased participatory research (CBPR) methods, and colonial scientific research strategies in the design, implementation, and evaluation of randomized controlled trials (RCTs) with American Indian (AI) communities $(1,2)$. The Center for American Indian and Rural Health Equity (CAIRHE) at Montana State University in Bozeman, Montana, is tasked with the design, implementation, and evaluation of CBPR RCTs with Tribal Nations. In this article, we assess the implementation of CBPR principles and practices in the following RCTs:

- Nen ŨnkUmbi/EdaHiYedo (“We Are Here Now”): March 2019-September 2023

- Báa nnilah: September 2017-January 2020

- Healthy Children, Strong Families 2: February 2013-April 2017

CAIRHE's work with Tribal Nations is organized into 3 domains - epistemologic, methodologic, and analytic - to conceptualize the integration of Indigenous and colonial research systems into RCTs. Epistemologic conflicts arise when RCTs, the gold standard for causal interpretation in colonial science (ie, science grounded in the white, predominately Judeo-Christian ideals of the nonIndigenous culture), are prioritized over Indigenous or other knowledge systems (ie, knowledge that comes from local communities) (3-5). Methodologic complexities must be negotiated when conducting RCTs with AI communities (6), because they are frequently geographically isolated, under-resourced, and mistrustful of outside researchers. These issues make engagement, recruitment, and retention in RCTs challenging (7). Furthermore, control groups may be deemed culturally inappropriate by tribal members, given a traditional culture of collectivism that values inclusion and sharing of benefits $(3,8-10)$. Analytic challenges threaten established concepts of validity and reliability in RCTs designed by using colonial science methods (11). For example, RCTs with Indigenous communities may include culturally distinct groups and small populations. These sample characteristics may result in underpowered analyses that call into question external validity and generalizability (12). Thus, analytic strategies that include alternative designs, mixed methods, and statistical computations to maximize power are warranted (13). In addition, RCTs with AI communities may require longer timelines to address tribal norms regarding research sovereignty and ethics (14).

\section{Purpose and Objectives}

Given these issues, we aim to offer insight to support the implementation of RCTs that join social context and human agency with CBPR, Indigenous knowledge systems, and the rigors of RCT designs (15). We discuss our methods and the strengths and challenges of 3 CBPR RCTs in varying implementation stages in culturally distinctive Tribal Nations as examples of how we addressed our epistemologic, methodologic, and analytic differences. More information on the epistemology, methods, and analytics used in our CBPR RCTs is presented in Table 1.

\section{Intervention Approach}

\section{Project 1: Nen ŨnkUmbi/EdaHiYedo ("We Are Here Now" or N/E)}

Sexual and reproductive health (SRH) disparities are higher in AI youth than any other adolescent population in the United States (16-19). Research documents that SRH disparities among AI youth are markers of underlying issues at the individual, family, school, community, and systems levels in AI communities that warrant novel, multifaceted community-based interventions (20-22). N/E is a multilevel, multicomponent, mixed-methods SRH intervention that was developed as a result of a 14-year collaborative research partnership between the Fort Peck Tribes and researchers at Montana State University. The RCT design is based on Fort Peck tribal members' desire to implement a holistic SRH intervention for AI youth aged 14 to 18. The conceptual framework for N/Es conceptual framework is CBPR, and its theoretical framework is Ecological Systems Theory. A community advisory board of 6 Fort Peck tribal members provided oversight and guidance for the intervention.

N/E includes 1) a school-based SRH curriculum called "Native Stand," designed to address individual-level factors that lead to sexual risk behaviors; 2) a family-level curriculum called "Native Voices," tailored to increase communication between adult family members and youth about SRH topics; 3) a cultural mentoring component at the community level that connects AI youth with elders to discuss traditional AI beliefs and practices about SRH; and 4) a systems-level component that works with the Fort Peck epidemiologic team, a multisectoral network of health care providers that delivers SRH services to AI youth to increase coordinate and access to SRH services for AI youth. The systems-level component is based on the Centers for Disease Control and Prevention's Evidence-Based Clinical Best Practices for Family Planning Services for Adolescents, which for the purposes of N/E was adapted by the Fort Peck epidemiologic team and Montana State

\footnotetext{
The opinions expressed by authors contributing to this journal do not necessarily reflect the opinions of the U.S. Department of Health and Human Services, the Public Health Service, the Centers for Disease Control and Prevention, or the authors' affiliated institutions.
} 
University (MSU) researchers for application with the Fort Peck Tribes (23).

N/E's school, parent, and cultural mentoring components are evaluated using a cluster-randomized, stepped-wedge design. In the stepped-wedge design for N/E, the 5 schools that Fort Peck AI youth attend are considered clusters that are randomly assigned to the intervention one at a time, with all schools eventually being assigned (24-26). The 5 schools are located in culturally distinct, separate communities throughout the reservation, mitigating the potential for cross-contamination. Our selection of a steppedwedge design to evaluate N/E is consistent with tribal members' desires that all adolescents aged 14 to 18 years receive the intervention, as well as providing the opportunity for comparisons between school clusters that have received N/E and those that have not. The systems-level component of $\mathrm{N} / \mathrm{E}$ is measured qualitatively, and N/E has completed its first year of intervention implementation in one of the schools on the Fort Peck Reservation.

\section{Project 2: Báa nnilah}

The Apsáalooke (Crow) language phrase Báa nnilah, translates to "advice or instructions for life received from others" in English. The Báa nnilah program is a chronic illness self-management study funded by an R01 grant from the National Institute on Minority Health and Health Disparities (NIMHD) that tests the effects of the intervention versus usual care by using a wait-list control group design. It was conducted among 211 randomly assigned AI men and women aged 25 years or older who have chronic illness and live on the Apsáalooke Reservation. To mitigate contamination, participants were assigned to intervention and control groups by using cluster randomization, where participants could select to be randomized with others who were in their household or who were closely related. In Montana, AI individuals die 14 years earlier from heart disease than people who are not AI, 11 years for those with diabetes, and 12 years for those with cerebrovascular disease (27). Despite their potential to lower mortality rates and improve quality of life, existing programs that address chronic illness management fail because they are not consonant with AI culture (28).

\section{Project 3: Healthy Children, Strong Families 2 (HCSF2)}

Obesity rates in AI children are among the highest of all races and ethnicities, and obesity greatly increases the risk of later chronic disease (29). HCSF2 was an NHLBI R01-funded RCT of a healthy lifestyle intervention for AI families with children aged 2 to 5 years. HCSF2 targeted multiple healthy lifestyle and obesity prevention goals; the methods are described in detail elsewhere (30). The HCSF2 design was based on an initial, smaller RCT interven- tion designed with 4 Wisconsin communities, and after achieving positive results it was expanded to the larger national RCT with 5 AI communities (30). In HCSF2, all 5 participating communities did not want to have a passive control group, so a modified crossover design was chosen with an active control intervention that focused on safety. Safety was chosen because accidents and injuries are the leading cause of illness and death in AI children in this age group, and it was proposed by one of our long-standing partner communities as being a good control group (31).

Families with young children from 5 AI communities nationwide were randomly assigned to a child safety control group ("Safety Journey") or to a healthy lifestyle intervention ("Wellness Journey") for 1 year. Members of the latter group were mailed a monthly intervention toolkit that focused on a healthy lifestyle, augmented with social support through Facebook and text messaging. Families in the child safety control group received monthly safety newsletters, with additional mailed books and supplies. All families randomly assigned to the intervention group in year 1 received the control intervention in year 2, and families randomly assigned to the control group in year 1 received the wellness intervention in year 2. Families were assigned to start either in the Wellness Journey or the Safety Journey and stratified by tribal site and child weight status (overweight vs healthy weight). Random assignment was conducted by the REDCap data management system (Vanderbilt University) using a permuted block strategy. Between-group differences in primary outcomes (adult body mass index [BMI] and child BMI $z$-score) and secondary outcomes (health behaviors) were assessed after year 1, which functioned as a traditional RCT, and again after year 2 (30).

The RCTs met CONSORT guidelines for clinical trials (32). All 3 of our RCTs were conducted within a CBPR framework, having been developed with extensive tribal support and tribal-academic partnerships ranging from 5 to 20 years. The 3 RCTs also had community advisory boards that provided oversight, direction, and cultural knowledge for the studies. The incorporation of colonial science RCT designs, CBPR, and expertise based on tribal culture in the 3 studies informed the integration of Indigenous ways of addressing health disparities and colonially defined, scientifically rigorous research with Tribal Nations (1).

Ethical approval for the RCTs depended on the ethical approval process required by the Tribal Nations in which the RCTs took place. In some instances, Tribal Nations had an established institutional review board (IRB), which provided ethical approval for the studies. In other instances, there was no established tribal IRB and the project was approved by the tribal council. The tribal ethical approvals obtained for our RCTs underscore the importance of Tribal Nations' research governance authority, their role as stewards and keepers of research conduct on their lands and with their

The opinions expressed by authors contributing to this journal do not necessarily reflect the opinions of the U.S. Department of Health and Human Services, the Public Health Service, the Centers for Disease Control and Prevention, or the authors' affiliated institutions. 
people, and their rights to make decisions and control the research they are involved with $(33,34)$. Finally, the RCTs received approval from the IRB at MSU (Projects 1 and 2) or the University of Wisconsin School of Medicine and Public Health (Project 3).

\section{Evaluation Methods}

We used a multiple case study research design to examine the ways in which Tribal Nations and CAIRHE researchers collaborated using CBPR to develop and implement RCTs $(35,36)$. Several steps were taken to facilitate this process. First, CAIRHE researchers met to discuss implementing RCTs in which, at the request of our tribal partners, all eligible tribal members in the study population would be included in the intervention, thereby negating the role of a control group. This conversation led to a broader discussion on how CBPR principles and practices are used to assess, negotiate, and determine the most effective intervention strategy that honors tribal interests, needs, and Indigenous worldviews while maintaining the integrity of the research protocols inherent in conducting RCTs. Second, on the basis of this discussion, we generated a list of questions to discuss with our community partners about the process undertaken by each of the 3 tribal-academic partnerships to arrive at their chosen RCT design (Box). Third, community partners and CAIRHE researchers met to discuss the list of questions and identify the pertinent issues that went into selecting our respective RCTs. Fourth, CAIRHE researchers reviewed and discussed the main themes that emerged from the conversations with our community partners. We identified 3 research design concepts - epistemology, methodology, and analytics - that are central to understanding and determining the integration of CBPR with the development and implementation of an RCT in Tribal Nations. Finally, community partners and CAIRHE researchers finalized the main research design concepts and determined the strengths and weaknesses of their respective RCTs.

\footnotetext{
Box. Community-Based Participatory Research and Randomized Controlled Trial (RCT) Development Discussion Questions for Community Partners and Center for American Indian and Rural Health Equity Researchers

-What is your research project?

- What ethical concerns motivated your research design and how did you identify them?

- What obstacles did/do you face in setting up an RCT?

- What conversations did you have with the community (community stakeholders or your community advisory board)?

- At what stage of the partnership were you ready to implement an RCT?

-What statistical methods did you use?

-What were the pros and cons of how you ultimately designed the RCT?
}

- Which RCT did you want and which did you get?

- What lessons learned and suggestions/tips do you have for researchers approaching an RCT in a tribal community for the first time?

\section{Results}

We present our results starting with a newly established CBPR RCT and closing with a completed CBPR RCT. The studies varied in size and scale from tribally based (Báa nnilah, $\mathrm{N}=211$ and $\mathrm{N} / \mathrm{E}, \mathrm{N}=451$ ) to nationally based (HCSF $2, \mathrm{~N}=450$ child-caregiver dyads), with each targeting different age groups: children (aged 2-5 years and their caregivers), adolescents (aged 14-18 years), and adults (aged 24-82 years) (Table 2). Collectively, our findings reflect a diverse range of CBPR RCT study designs in Tribal Nations. For each study, we show the strengths and challenges identified in the research design.

\section{Project 1: Nen ŨnkUmbi/EdaHiYedo ("We Are Here Now," or N/E)}

Strengths. N/E is grounded in a long-standing research partnership between the Fort Peck Tribes and MSU researchers. N/E is modeled after a holistic, inclusionary Assiniboine and Sioux worldview that honors the individual, the importance of family, the need to instill and revitalize cultural beliefs and values in tribal youth, and the awareness that large and complex systems such as schools and health care services influence the SRH of young people. N/E's other strengths are the adaptation and efficacy testing of 2 previously developed curricula for tribal youth and families, the integration of an existing tribal cultural mentoring program, and the enhancement of SRH services for AI youth following evidenced-based clinical practices for adolescent family planning services.

Challenges. Challenges to N/E include 1) the use of self-reported measures of sexual risk behaviors to assess our primary, secondary, and tertiary outcomes; 2) social desirability bias because of research participants' familiarity with the community members implementing N/E; 3) the potential of recruitment and retention of youth and families to affect sample size and statistical power; 4) the possibility of contamination to sites that have not yet entered or completed the intervention; and 5) the possibility of an unobserved 3-way interaction existing by intervention cluster under the stepped-wedge design.

\section{Project 2: Báa nnilah}

Strengths. Báa nnilah originated in the community and uses trusted community members to facilitate it. Similar to the other RCTs, we are building on a long-term partnership. Intervention methods

The opinions expressed by authors contributing to this journal do not necessarily reflect the opinions of the U.S. Department of Health and Human Services, the Public Health Service, the Centers for Disease Control and Prevention, or the authors' affiliated institutions. 
are centered on Apsáalooke cultural strengths, and content is based on our conceptual framework of influencers of self-care related to chronic illness that came from community interviews.

Challenges. Community members in the intervention group shared information with wait-list control group members. Although contamination is a problem during data analysis in an RCT, sharing information between groups is seen, from the community's perceptive, as a strength and is in keeping with the Apsáalooke cultural value of inclusiveness. We gathered data on contamination to assess the impact of sharing. Similar to the other 2 projects, the ability for participants to attend all of the program gatherings was affected by inclement weather, lack of transportation, travel conflicts, and deaths in the community.

\section{Project 3: Healthy Children, Strong Families 2 (HCSF2)}

Strengths. This multisite, 5-state trial had a strongly inclusive RCT design that enabled us to have $100 \%$ recruitment and excellent family retention in the study, with loss of only $16 \%$ over 2 years (30). The safety active control group was well received, as it allowed for no passive control communities and no wait lists for families, which enhanced family recruitment and reduced attrition. The AI value of inclusivity was used in teaching components appropriate for both adults and children in the family, and these components incorporated culturally appropriate books, recipes, and activities. Each community had a local HCSF2 community coordinator who was responsible for helping families with survey completion, doing anthropometric measures, and creating local Facebook content. These local coordinators were critical to keeping families connected and reducing attrition. Sites with stable local coordinators were able to meet or exceed recruitment targets. A central university site coordinated the study and distributed all mailed toolkit materials, reducing the burden for individual sites. All families had interest in and engagement with the study materials, and focus groups described substantial benefits to study participation.

Challenges. Conducting a multisite, randomized trial using community-engaged approaches requires flexibility. Geographic dispersion of the 5 communities in 3 time zones necessitated significant planning and made it impossible to use more robust outcome measures such as accelerometry. In addition, it was important to engage in discussions with more potential sites than needed because of dropout during the early stages of project planning. Every site presented a different challenge. Flexibility with local hiring and staff turnover, site timing, and recruitment were necessary. In addition, because of the community value for inclusivity and wish not to stigmatize children, we had to stratify the randomization to include equal numbers of children above and below the
$85 \%$ BMI in each group, thus reducing our ability to show change in BMI. However, this stratification improved recruitment and emphasized the importance of prevention. Lastly, because all families viewed themselves as being in the HCSF2 study, some families may have started to make healthy lifestyle changes during the first year despite being in the control group.

\section{Implications for Public Health}

Respective tribal-academic partnerships demonstrated that longterm CBPR collaborations can mitigate the epistemologic, methodologic, and analytic complexities of conducting RCTs with AI communities (37-40). CBPR provides a set of principles and guidelines that help communities and researchers build equitable, mutually beneficial, and long-term partnerships to create locally applicable knowledge (41). AI communities and research partners may, however, approach these collaborations from different perspectives to design and implement studies that fit community priorities and satisfy salient cultural contexts and specific RCT conventions (42). Recognizing the variation in the types of CBPR RCTs presented here, we identified some commonalities as cornerstones of successful CBPR RCTs (Table 3). By so doing, we generated new knowledge that supports efforts to decolonize research methods with Indigenous peoples and develop new gold standards for RCTs with Tribal Nations (2).

First, long-standing community-researcher relationships were identified as foundational to the development, implementation, and evaluation of CBPR RCTs. All partnerships presented had 5 to 20 years of continuous successful engagement to establish trust and build capacity. The success of our respective RCTs was based on the substantial amount of community engagement before the RCTs' design and implementation, which allowed the researchers to develop an understanding of cultural beliefs and practices and tribal community dynamics and processes. Multiple studies conducted in AI communities have confirmed the importance of tribal support and trusting relationships to ensure project success $(43,44)$. However, we conclude that the established depth of trust in partnerships developed over multiple years fostered an open dialogue between community members and researchers that led to the strengths in our respective studies, including 1) integrating the best-suited RCT design with the cultural beliefs and practices, structural systems, and health needs of the community; 2) the ability of our partnerships to withstand the test of time and changes in tribal leadership; 3) exchange of Indigenous knowledge and colonial science to support co-learning between community members and researchers; and 4) the capacity to find solutions to challenges that met the cultural, structural, and health needs of the community in addition to the rigor of RCT designs.

The opinions expressed by authors contributing to this journal do not necessarily reflect the opinions of the U.S. Department of Health and Human Services, the Public Health Service, the Centers for Disease Control and Prevention, or the authors' affiliated institutions. 
Second, in our CBPR RCTs, the values and definition of success differed between the communities and researchers. For example, there was the potential for Báa nnilah participants in the intervention group to share information with wait-list control group members. From a purely colonial science research perspective, this type of "contamination" compromises the validity of the study's results. From a community perspective, sharing information among groups is culturally appropriate and in harmony with an Indigenous worldview of collectivism. However, other concepts of validity warrant exploration here. In CBPR, validity of a study can be based on such attributes as the characteristics of the partnership in which a study is conducted and the process the partnership went through to design, implement, and evaluate a study $(39,45)$. Thus, future tribal-academic partnerships that implement RCTs may consider how to establish validity within the context of their research.

Similarly, inherent in RCTs is the need for some form of control group or groups in which a portion of a population either does not receive the intervention or receives a placebo. From the perspective of the communities involved in these RCTs, the idea that a person or group of people would not receive something that other people receive, thereby dividing people into those that have and those that do not have, is culturally unacceptable. As academic partners, we found ourselves needing to identify RCT designs that ensured that all tribal members who were eligible for the study would be able to participate.

Our final differing area of success is related to social desirability. In terms of research, social desirability is viewed as a limitation that negatively affects research results because it suggests that participants will respond in a certain way if they know the members of the research team who are collecting the data. In contrast, tribal members will participate in research studies specifically because they know and feel comfortable with members of the research team, thereby enhancing not only the depth of responses given but also the recruitment and retention of participants needed in RCTs.

Our examples of the difference between the scientific needs of the researchers and cultural needs of the Tribal Nations in which our interventions are implemented underscores emergent intervention science research. Our 3 RCTs highlight current intervention science research with Tribal Nations that supports culture as an organizing factor in how RCTs are designed, implemented, and evaluated with Indigenous communities (46). We recommend researchers working with Tribal Nations to design, implement, and evaluate RCTs identify and prepare for how to address diverse approaches and perspectives to research in their work together to generate new knowledge related to intervention science with Tribal Nations.
Third, the path toward our respective CBPR RCTs generated a common respect for the importance of diverse knowledge systems. Dickerson et al illustrate strategies for the integration of culturally centered interventions and colonial-based research practices and theories with AI communities (2). Their work outlined techniques such as including talking circles, community partnership committees, and tribal leader and elder knowledge and expertise to adapt non-Indigenous research strategies such as focus groups, surveys, and interviewing. In our experiences, community members and university researchers shared multiple conversations over several years in which we grappled with integrating Indigenous wisdom, traditional knowledge systems and ways of viewing the world, and colonial science knowledge systems. Furthermore, today there is a contemporary culture on reservations that is neither traditional nor modern but rather a merging of the two. This reality underpins how things actually happen on reservations, which supports the importance of evaluating how an intervention was implemented versus what was planned for intervention implementation $(37,45)$. Contemporary reservation culture creates yet another form of knowledge to be understood and integrated into the design, implementation, and assessment of RCTs with Tribal Nations. This multifold process of sifting through Indigenous wisdom, traditional knowledge systems, contemporary reservation culture, and colonial scientific methods required reflection and critique of established RCT methods to create new standards for measuring the attainment of our CBPR RCT aims.

It is critical for those working in designing clinical trials and for funders to understand that in underserved communities, colonial definitions of trial success with primary, secondary, and tertiary outcomes that are strictly defined and measured may not capture the real success of an RCT in a tribal community. For example, although HCSF2 did not show a difference in the primary outcome of BMI $z$-score change in children, family engagement with the project was substantial and led to lifestyle improvements and readiness to change, as well as the unanticipated positive outcome of families spending more time together. Several Tribal Nations also experienced an increased interest and commitment to promoting child and family health, thereby likely contributing to long-term health improvements in their communities. Engaging as a community in a health improvement trial in itself can be beneficial for that community, and this success is not necessarily dependent on the scientific definition of success for the project.

Our study has limitations. The interventions presented are in different stages of implementation. In addition, the interventions address different age groups and health disparities, and they take place in culturally and socioecologically diverse Tribal Nations in Montana and other areas of the United States. The interventions also use 3 different RCT designs with CBPR being the foundation-

\footnotetext{
The opinions expressed by authors contributing to this journal do not necessarily reflect the opinions of the U.S. Department of Health and Human Services, the Public Health Service, the Centers for Disease Control and Prevention, or the authors' affiliated institutions.
} 
al framework for each study. These distinct variations in our respective interventions may make it difficult to generalize our identified epistemologic, methodologic, and analytic issues to other tribal settings. However, we were able to identify common cornerstones for successful CBPR RCTs with AI communities even with our interventions' apparent contrasts. Our identified conclusions can serve as recommendations for future CBPR intervention science practices with Indigenous groups.

We have presented the epistemologic, methodologic, and analytic issues inherent in the design, implementation, and evaluation of CBPR RCTs with Tribal Nations and the strengths and challenges that our differing CBPR RCTs encountered. On the basis of our collective experiences, we believe that future CBPR RCT tribal-academic partnerships must understand several key points. First, it is critical to take the time (ie, several years) to establish trusted, meaningful CBPR partnerships before embarking on RCTs with Tribal Nations. Although extensive community engagement before conducting an RCT with a tribal community may seem unrealistic from an academic perspective, strong relationships between tribal members and researchers are foundational to working through the complexities of RCT research. Second, there is a need to balance community interests and desires with expectations established by funders, such as the National Institutes of Health (NIH), to meet the scientific rigor of an RCT. The balance between community needs, colonial-focused research precision, and funding expectations can be sorted out through a combination of iterative communication between tribal members, researchers, and funders, as well as promoting co-learning with tribal members, researchers, and policy makers in funding agencies that support the science of RCTs with Indigenous communities. Third and finally, success in CBPR RCTs must be measured using both tribal community concepts of success and positive outcomes and outcomes found in standard colonial scientific research practices. This broader definition of success will more significantly benefit the communities involved and may lead to improved intervention recruitment and sustainability.

\section{Acknowledgments}

We are grateful for the partnerships with our respective Tribal Nations. It is their belief in and commitment to their people and our collaborative research that ensures the achievements of CBPR RCTs. The CBPR RCTs presented in this article received the following awards: Project 1, Elizabeth Rink (Principal Investigator), NIH NIMHD, award no. R01MD012761-01; Project 2, Alma McCormick and Suzanne Held (Principal Investigators), NIH, NIMHD award no. U01MD010619; and Project 3, Alex Adams (Principal Investigator), NIH National Heart, Lung, and Blood Institute award no. R01HL114912. CAIRHE is supported by the National
Institute of General Medical Sciences of the NIH under award no. P20GM104417. Clinical trials registration numbers are Project 1, NCT03694418; Project 2, NCT03036189; and Project 3, NCT01776255.

We also thank Amy Talcott and Shannon Holder for their review and editing of the manuscript. The authors declare no potential conflicts of interest with respect to the research, authorship, and publication of this article. No copyrighted instruments or tools were used in this research.

\section{Author Information}

Corresponding Author: Elizabeth Rink, PhD, MSW, Department of Health and Human Development, Montana State University, 318 Herrick Hall, Bozeman, MT 59717. Telephone: 406-9943833. Email: elizabeth.rink@montana.edu.

Author Affiliations: ${ }^{1}$ Department of Health and Human Development, Montana State University, Bozeman, Montana. ${ }^{2}$ Department of Sociology and Anthropology, Montana State University, Bozeman, Montana. ${ }^{3}$ Messengers for Health, Crow Indian Reservation, Crow Agency, Montana. ${ }^{4}$ Fort Peck Community College, Fort Peck Indian Reservation, Poplar, Montana. ${ }^{5}$ Center for American Indian and Rural Health Equity, Montana State University, Bozeman, Montana.

\section{References}

1. Crump AD, Etz K, Arroyo JA, Hemberger N, Srinivasan S. Accelerating and strengthening Native American health research through a collaborative NIH initiative. Prev Sci 2020; 21(1,Suppl 1):1-4.

2. Dickerson D, Baldwin JA, Belcourt A, Belone L, Gittelsohn J, Keawe'aimoku Kaholokula J, et al. Encompassing cultural contexts within scientific research methodologies in the development of health promotion interventions. Prev Sci 2020; 21(1,Suppl 1):33-42.

3. Henry D, Tolan P, Gorman-Smith D, Schoeny M. Alternatives to randomized control trial designs for community-based prevention evaluation. Prev Sci 2017;18(6):671-80.

4. Walters KL, Johnson-Jennings M, Stroud S, Rasmus S, Charles B, John S, et al. Growing from our roots: strategies for developing culturally grounded health promotion interventions in American Indian, Alaska Native, and Native Hawaiian communities. Prev Sci 2020;21(1,Suppl 1):54-64.

5. Smith LT. Decolonizing methodologies: research and indigenous peoples. London (UK): Zed Books Ltd; 2013.

The opinions expressed by authors contributing to this journal do not necessarily reflect the opinions of the U.S. Department of Health and Human Services, the Public Health Service, the Centers for Disease Control and Prevention, or the authors' affiliated institutions. 
6. Chino M, Debruyn L. Building true capacity: indigenous models for indigenous communities. Am J Public Health 2006; 96(4):596-9.

7. Nicholson LM, Schwirian PM, Groner JA. Recruitment and retention strategies in clinical studies with low-income and minority populations: Progress from 2004-2014. Contemp Clin Trials 2015;45(Pt A):34-40.

8. Fisher PA, Ball TJ. Tribal participatory research: mechanisms of a collaborative model. Am J Community Psychol 2003; 32(3-4):207-16.

9. Cochran PA, Marshall CA, Garcia-Downing C, Kendall E, Cook D, McCubbin L, et al. Indigenous ways of knowing: implications for participatory research and community. Am J Public Health 2008;98(1):22-7.

10. Cajete G. Native science: Natural laws of interdependence. Santa Fe (NM): Clear Light Publishers; 2000.

11. Whitesell NR, Mousseau A, Parker M, Rasmus S, Allen J. Promising practices for promoting health equity through rigorous intervention science with indigenous communities. Prev Sci 2020;21(1,Suppl 1):5-12.

12. Allen J, Rasmus SM, Fok CCT, Charles B, Henry D; Qungasvik Team. Multi-level cultural intervention for the prevention of suicide and alcohol use risk with Alaska Native youth: a nonrandomized comparison of treatment intensity. Prev Sci 2018;19(2):174-85.

13. Henry D, Fok CCT, Allen J. Why small is too small a term: prevention science for health disparities, culturally distinct groups, and community-level intervention. Prev Sci 2015; 16(7):1026-32.

14. Harding A, Harper B, Stone D, O’Neill C, Berger P, Harris S, et al. Conducting research with tribal communities: sovereignty, ethics, and data-sharing issues. Environ Health Perspect 2012;120(1):6-10.

15. Hansen ABG, Jones A. Advancing 'real-world' trials that take account of social context and human volition. Trials 2017; 18(1):531.

16. Centers for Disease Control and Prevention. Teen pregnancy rates, 2013; 2013. https://cdc.gov/teenpregnancy/pdf/teenpregnancy-rates-2013.pdf. Accessed September 28, 2020.

17. Centers for Disease Control and Prevention. Health Disparities in HIV/AIDS, Viral Hepatitis, STDs, and TB: Centers for Disease Control and Prevention; 2017. https:/www.cdc.gov/ nchhstp/healthdisparities/americanindians.html. Accessed September 28, 2020.

18. Centers for Disease Control and Prevention. STDs and minorities. http://www.cdc.gov/std/stats 14/minorities.htm. Accessed September 28, 2020.
19. Centers for Disease Control and Prevention. HIV and American Indians and Alaska Natives; 2018. http:// www.cdc.gov/hiv/group/racialethnic/aian/index.html. Accessed September 28, 2020.

20. Rink E, Ricker A, FourStar K, Anastario M. Unzip the truth: results from the Fort Peck Men's Sexual Health Intervention and Evaluation study. Am J Sex Educ 2016;11(4):306-30.

21. Rink E, Ricker A, FourStar K, Hallum-Montes R. "A Balance That We Walk": characteristics, attributes, and behaviors that promote healthy American Indian heterosexual couple relationships. J Fam Issues 2018;39(3):817-40.

22. Rink E, FourStar K, Anastario MP. The relationship between pregnancy prevention and STI/HIV prevention and sexual risk behavior among American Indian men. J Rural Health 2017; 33(1):50-61.

23. Centers for Disease Control and Prevention. Teen pregnancy rates, 2013; 2013. https://cdc.gov/teenpregnancy/pdf/preventteen-pregnancy/fact-sheet-contraceptive-reproductive -healthservices-teens_tagged-508.pdf. Accessed September 28, 2020.

24. Mdege ND, Man M-S, Taylor Nee Brown CA, Torgerson DJ. Systematic review of stepped wedge cluster randomized trials shows that design is particularly used to evaluate interventions during routine implementation. J Clin Epidemiol 2011; 64(9):936-48.

25. Woertman W, de Hoop E, Moerbeek M, Zuidema SU, Gerritsen DL, Teerenstra S. Stepped wedge designs could reduce the required sample size in cluster randomized trials. J Clin Epidemiol 2013;66(7):752-8.

26. Hemming K, Haines TP, Chilton PJ, Girling AJ, Lilford RJ. The stepped wedge cluster randomised trial: rationale, design, analysis, and reporting. BMJ 2015;350(feb06 1):h391.

27. Montana Department of Public Health and Human Services. Montana vital statistics. In: Public Health and Safety Division Report. Helena (MT): MDPHHS; 2011.

28. Ory MG, Ahn S, Jiang L, Lorig K, Ritter P, Laurent DD, et al. National study of chronic disease self-management: six-month outcome findings. J Aging Health 2013;25(7):1258-74.

29. Deen JF, Adams AK, Fretts A, Jolly S, Navas-Acien A, Devereux RB, et al. Cardiovascular disease in American Indian and Alaska Native youth: unique risk factors and areas of scholarly need. J Am Heart Assoc 2017;6(10):e007576.

30. Tomayko EJ, Prince RJ, Cronin KA, Parker T, Kim K, Grant VM, et al. Healthy Children, Strong Families 2: A randomized controlled trial of a healthy lifestyle intervention for American Indian families designed using community-based approaches. Clin Trials 2017;14(2):152-61.

31. Berns RM, Tomayko EJ, Cronin KA, Prince RJ, Parker T, Adams AK. Development of a culturally informed child safety curriculum for American Indian families. J Prim Prev 2017; 38(1-2):195-205.

The opinions expressed by authors contributing to this journal do not necessarily reflect the opinions of the U.S. Department of Health and Human Services, the Public Health Service, the Centers for Disease Control and Prevention, or the authors' affiliated institutions. 
32. Moher D, Hopewell S, Schulz KF, Montori V, Gøtzsche PC, Devereaux PJ, et al.; CONSORT. CONSORT 2010 explanation and elaboration: updated guidelines for reporting parallel group randomised trials. Int J Surg 2012;10(1):28-55.

33. Christopher S, Villegas M, Daulton C, editors. 'Walk softly and listen carefully': building research relationships with tribal communities. Washington (DC): National Congress of American Indians; 2012.

34. National Congress of American Indians, Policy Research Center. Research policy update: tribal implications of the revised common rule and NIH sIRB policy; 2017.

35. Yin RK. Case study research and applications: design and methods. Thousand Oaks (CA): Sage Publications; 2017.

36. Gillham B. Case study research methods. London (UK): Bloomsbury Publishing; 2000.

37. Jernigan VBB, Jacob T, Styne D,; Tribal Community Research Team. The adaptation and implementation of a communitybased participatory research curriculum to build tribal research capacity. Am J Public Health 2015;105(Suppl 3):S424-32.

38. Christopher S, Saha R, Lachapelle P, Jennings D, Colclough $\mathrm{Y}$, Cooper $\mathrm{C}$, et al. Applying indigenous community-based participatory research principles to partnership development in health disparities research. Fam Community Health 2011; 34(3):246-55.

39. Laveaux D, Christopher S. Contextualizing CBPR: Key Principles of CBPR meet the Indigenous research context. Pimatisiwin 2009;7(1):1.

40. Thomas LR, Rosa C, Forcehimes A, Donovan DM. Research partnerships between academic institutions and American Indian and Alaska Native Tribes and organizations: effective strategies and lessons learned in a multisite CTN study. Am J Drug Alcohol Abuse 2011;37(5):333-8.

41. Israel BA, Parker EA, Rowe Z, Salvatore A, Minkler M, López $\mathrm{J}$, et al. Community-based participatory research: lessons learned from the Centers for Children's Environmental Health and Disease Prevention Research. Environ Health Perspect 2005;113(10):1463-71.

42. Glover M, Kira A, Johnston V, Walker N, Thomas D, Chang $\mathrm{AB}$, et al. A systematic review of barriers and facilitators to participation in randomized controlled trials by Indigenous people from New Zealand, Australia, Canada and the United States. Glob Health Promot Educ 2015;22(1):21-31.

43. Christopher S, Watts V, McCormick AK, Young S. Building and maintaining trust in a community-based participatory research partnership. Am J Public Health 2008; 98(8):1398-406.

44. Yancey AK, Ortega AN, Kumanyika SK. Effective recruitment and retention of minority research participants. Annu Rev Public Health 2006;27(1):1-28.
45. Wallerstein N, Duran B, Oetzel JG, Minkler M. Communitybased participatory research for health: advancing social and health equity. Hoboken (NJ): John Wiley \& Sons; 2017.

46. Rasmus SM, Whitesell NR, Mousseau A, Allen J. An intervention science to advance underrepresented perspectives and indigenous self-determination in health. Prev Sci 2020; 21(Suppl 1):83-92.

The opinions expressed by authors contributing to this journal do not necessarily reflect the opinions of the U.S. Department of Health and Human Services, the Public Health Service, the Centers for Disease Control and Prevention, or the authors' affiliated institutions. 


\section{Tables}

Table 1. Project Overview, Epistemology, Methodology, and Analytics Related to Research Design for Randomized Controlled Trials, Case Studies Conducted in 3 US Tribal Nations

\begin{tabular}{|c|c|c|c|}
\hline Category & $\begin{array}{c}\text { Project 1: Nen ŨnkUmbi/EdaHiYedo } \\
\text { ("We Are Here Now") }\end{array}$ & Project 2: Báa nnilah & Project 3: Healthy Children, Strong Families 2 \\
\hline $\begin{array}{l}\text { Project } \\
\text { Overview }\end{array}$ & $\begin{array}{l}\text { - All 15- to 18-year-old tribal member youths } \\
\text { living on the Fort Peck Reservation receive } \\
\text { intervention using a stepped-wedge design. } \\
\text { - Aim is to reduce SRH disparities by } \\
\text { increasing birth control use, reducing number } \\
\text { of sex partners, delaying onset of sexual } \\
\text { intercourse, increasing parent-child } \\
\text { communication about SRH, strengthening } \\
\text { connections to traditional cultural beliefs, and } \\
\text { expanding access to SRH services for youth on } \\
\text { the Fort Peck Reservation. }\end{array}$ & $\begin{array}{l}\text { - Members of the Absáalooke (Crow) } \\
\text { Tribe aged } 25 \text { or older who have } \\
\text { chronic illnesses are eligible to } \\
\text { participate in the intervention. } \\
\text { - In Montana, Als who have chronic } \\
\text { illnesses die earlier than Whites. This } \\
\text { program aims to erase this disparity, } \\
\text { improve quality of life, increase } \\
\text { satisfaction in and participation in } \\
\text { social roles and activities, decrease } \\
\text { social isolation, increase patient } \\
\text { activation, and decrease depression } \\
\text { among community members who have } \\
\text { chronic illness. }\end{array}$ & $\begin{array}{l}\text { - Intervention included caregivers with } 2 \text { - to } 5 \text {-year-old } \\
\text { children at } 4 \text { reservations and } 1 \text { urban Indian health } \\
\text { center. } \\
\text { - Goal was obesity prevention and healthy lifestyle } \\
\text { promotion by improving fruit and vegetable } \\
\text { consumption, physical activity, and sleep habits, and by } \\
\text { decreasing screen time, stress, and consumption of } \\
\text { sugared beverages and junk food. }\end{array}$ \\
\hline Epistemology & $\begin{array}{l}\text { - Strengthening of Assiniboine and Sioux } \\
\text { traditional beliefs and practices related to SRH, } \\
\text { families, and culture } \\
\text { - Integration of Assiniboine and Sioux } \\
\text { worldview with Ecological Systems Theory }\end{array}$ & $\begin{array}{l}\text { - Intervention methods co-developed } \\
\text { by partners include Crow-specific goal } \\
\text { setting, use of traditional stories in } \\
\text { intervention, and Crow-based } \\
\text { resilience exercise } \\
\text { - Participants meet in groups to } \\
\text { provide support to one another, } \\
\text { strengthening the traditional Crow } \\
\text { practice of people coming together and } \\
\text { visiting }\end{array}$ & $\begin{array}{l}\text { - Family-based intervention based on the Native } \\
\text { concept of elders teaching younger generations } \\
\text { - Designed by Al communities in partnership with } \\
\text { academic researchers } \\
\text { - Based on Social Cognitive Theory and Family } \\
\text { Systems Theory }\end{array}$ \\
\hline Methodology & $\begin{array}{l}\text { - Randomized controlled trial with stepped- } \\
\text { wedge design } \\
\text { - Developed based on previously conducted } \\
\text { community focus groups, key information } \\
\text { interviews, and a school-based youth survey } \\
\text { - Multilevel, multicomponent intervention } \\
\text { including “Native Stand" curriculum (individual } \\
\text { level), adaptation of "Native Voices" (family } \\
\text { level), cultural mentoring program (community } \\
\text { level), and adaption of CDC evidence-based } \\
\text { best clinical practices of SRH services for youth } \\
\text { (systems level) }\end{array}$ & $\begin{array}{l}\text { - All participants receive intervention } \\
\text { via wait-list control design } \\
\text { - Participants recruited through use of } \\
\text { Crow clan system and close kinship }\end{array}$ & $\begin{array}{l}\text { - Randomized controlled trial with modified crossover } \\
\text { design } \\
\text { - Multicomponent, home-based intervention with } 12 \\
\text { monthly mailed lessons for young families } \\
\text { - All families received wellness intervention and safety } \\
\text { intervention (active control) per community desire for } \\
\text { full inclusion } \\
\text { - Lessons themed on } 6 \text { healthy behaviors or on } 11 \\
\text { safety topics; each lesson included Al books, recipes, } \\
\text { and games } \\
\text { - Intervention supported by Facebook group and } \\
\text { biweekly text messages to caregivers } \\
\text { - Local site coordinators engaged families in survey } \\
\text { and anthropometric data collection every } 6 \text { months }\end{array}$ \\
\hline Analytics & $\begin{array}{l}\text { - Mixed-methods approach } \\
\text { - Surveys administered to youth and parents } \\
\text { to assess components at the individual, family, } \\
\text { and community levels } \\
\text { - Work plan and quarterly meetings used to } \\
\text { assess systems-level component } \\
\text { - Focus groups with youth, parents, school } \\
\text { personnel, SRH service providers, and mentors } \\
\text { held to assess fidelity and acceptability } \\
\text { - All data reviewed and interpreted with } \\
\text { community advisory board and Fort Peck/MSU- } \\
\text { based researchers }\end{array}$ & $\begin{array}{l}\text { - Mixed-methods design to gather } \\
\text { contextual data } \\
\text { - All qualitative data co-analyzed by } \\
\text { community and university partners } \\
\text { using co-developed methods } \\
\text { - Annual community meetings in } \\
\text { reservation districts held to share } \\
\text { information and gather input }\end{array}$ & $\begin{array}{l}\text { - Primary comparison will be supplemented by } \\
\text { analysis of covariance for BMI/zBMI at Year } 1 \text { with } \\
\text { randomization and BMI/zBMI at baseline as model } \\
\text { terms. } \\
\text { - Healthy behaviors and self-efficacy for behavior } \\
\text { change from baseline to Year } 1 \text { will be analyzed as } \\
\text { secondary outcomes. Focus groups were conducted to } \\
\text { access feasibility and acceptability of intervention. } \\
\text { Qualitative data collaboratively analyzed with } \\
\text { communities. } \\
\text { - Site-specific baseline data reports were given to } \\
\text { each tribe, and aggregated results will be given to each } \\
\text { community with time for community input before } \\
\text { publication. }\end{array}$ \\
\hline
\end{tabular}

Abbreviations: Al, American Indian; BMI, body mass index; CDC, Centers for Disease Control and Prevention; MSU, Montana State University; SRH, sexual and reproductive health; zBMI, BMI $z$-score.

The opinions expressed by authors contributing to this journal do not necessarily reflect the opinions of the U.S. Department of Health and Human Services, the Public Health Service, the Centers for Disease Control and Prevention, or the authors' affiliated institutions. 
Table 2. Participant Demographics, Case Studies of Implementing Randomized Controlled Trials in 3 US Tribal Nations

\begin{tabular}{|l|l|l|l|}
\hline Demographic Characteristic & \multicolumn{1}{|c|}{$\begin{array}{c}\text { Nen ŨnkUmbi/EdaHiYedo } \\
\text { (“We Are Here Now”) (N= 456) }\end{array}$} & $\begin{array}{c}\text { Báa nnilah } \\
(\mathrm{N}=211)\end{array}$ & \multicolumn{1}{|c|}{ Healthy Children Strong Families 2 (N = 450 Families) } \\
\hline Age & $14-18$ years & $24-82$ years & Children aged 2-5 years and their adult caregiver \\
\hline Sex, no. (\%) & $227(50)$ & $59(28)$ & Caregiver: 24 (5.3)/child: 224 (49.8) \\
\hline Male & $222(49)$ & $152(72)$ & Caregiver: 426 (94.7)/child: 226 (50.2) \\
\hline Female & $5(1)$ & NA & NA \\
\hline Neither male nor female & & $\begin{array}{l}\text { Crow } \\
\text { Reservation }\end{array}$ & $\begin{array}{l}\text { 4 tribal reservations (1 in the Northeast, 2 in upper Midwest, and 1 } \\
\text { primarily Amern Mountain region) and 1 urban clinic serving a }\end{array}$ \\
\hline & Fort Peck Reservation & &
\end{tabular}

Abbreviation: NA, not applicable. 
Table 3. Using Community-Based Participatory Research in Randomized Controlled Trials, Common Themes in Case Studies Conducted in 3 US Tribal Nations

\begin{tabular}{|l|l|}
\hline Theme & \multicolumn{1}{c|}{ Elements } \\
\hline $\begin{array}{l}\text { Long-standing } \\
\text { partnerships }\end{array}$ & $\begin{array}{l}\text { - 5- to 20-year partnerships } \\
\text { Open dialogue on the most appropriate RCT to meet tribal interests } \\
\text { - Strength of partnership to withstand the test of time and changes in tribal leadership and personnel } \\
\text { - Co-learning and sharing between tribal members and researchers } \\
\text { - Capacity to find solutions to meet tribal needs and the rigor of RCT designs }\end{array}$ \\
\hline $\begin{array}{l}\text { Diverse concepts } \\
\text { of success }\end{array}$ & $\begin{array}{l}\text { - Substantial community engagement before the design and implementation of an RCT can increase its success } \\
\text { - Hiring tribal members to work on implementation and data collection enhances the success of the RCT } \\
\text { - RCT research participants' sharing of information is in accordance with tribal cultural philosophies of inclusiveness }\end{array}$ \\
\hline $\begin{array}{l}\text { Respect for } \\
\text { diverse knowledge an RCT design that ensures all eligible tribal members have the opportunity to participate in the intervention } \\
\text { systems }\end{array}$ & $\begin{array}{l}\text { - Understanding and integrating traditional Indigenous knowledge systems and ways Indigenous people view the world with knowledge based } \\
\text { on a colonial worldview } \\
\text { - Marrying CBPR principles and practices with Indigenous cultural beliefs and practices and the rigors of RCT standards and requirements } \\
\text { modern } \\
\text { moring of traditional knowledge and colonial science knowledge with contemporary culture on reservations, which is neither traditional nor } \\
\text { research is conducted on their lands and with their peoples }\end{array}$ \\
\hline
\end{tabular}

Abbreviations: CBPR, community-based participatory research; RCT, randomized controlled trial.

The opinions expressed by authors contributing to this journal do not necessarily reflect the opinions of the U.S. Department of Health and Human Services, the Public Health Service, the Centers for Disease Control and Prevention, or the authors' affiliated institutions. 